\title{
Arterial Onyx Embolisation of Intracranial DAVFs with Cortical Venous Drainage
}

\author{
Jason Chew, Alain Weill, François Guilbert, Jean Raymond, Marie-Eve Audet, \\ Daniel Roy
}

\begin{abstract}
Purpose: To present our experience with the endovascular management of intracranial dural arteriovenous fistulas with direct cortical venous drainage by trans-arterial embolisation using Onyx. Materials \& Methods: Between January 2004 and April 2008 , 12 consecutive high grade intracranial dural arteriovenous fistulas (Cognard type III (eight patients) or IV (three patients)) were treated by trans-arterial embolisation with Onyx. The majority of cases were treated by Onyx embolisation alone. One case had additional embolisation with n-butyl-2-cyanoacrylate at the same session. Imaging follow-up was obtained in all but one patient (mean 3.6 months). Results: Nine patients had a technical success at the end of the embolisation procedure with complete angiographic exclusion of the fistula. Two patients had a small residual fistula at the end of embolisation, one of which had residual mild cortical venous drainage. Both were stable at follow-up angiography. One patient had a residual fistula supplied by the ophthalmic artery, which was thought to be unsafe to embolise and was sent for surgery, which was curative. In one patient the microcatheter ruptured, with a fragment of the distal microcatheter left in the occipital artery. No clinical complications were observed in this series at clinical follow-up (mean 3.3 months). Two patients were noted to have significant radiation dose. Conclusion: Endovascular management of intracranial dural arteriovenous fistulas with direct venous cortical drainage by trans-arterial Onyx embolisation is a safe and effective treatment according to our experience. Fluoroscopy times and radiation dose may be a concern.
\end{abstract}

RÉSUMÉ: Embolisation par voie artérielle d'Onyx dans les fistules durales artério-veineuses avec drainage veineux cortical. Objectif : Nous décrivons notre expérience du traitement endovasculaire par embolisation trans-artérielle d'Onyx des fistules durales artério-veineuses intracrâniennes avec drainage veineux cortical direct. Matériels et méthodes : Entre janvier 2004 et avril 2008, douze patients consécutifs porteurs de fistules artérioveineuses durales intracrâniennes de haut degré (type III de Cognard (8 patients) ou type IV (3 patients)) ont été traités par embolisation d'Onyx par voie artérielle. La majorité des cas ont été traités par embolisation d'Onyx seulement. Chez un patient une embolisation additionnelle de n-butyl-2cyanoacrylate (nBCA) a été effectuée au cours de la même session. Une imagerie a été obtenue chez tous les patients sauf un au cours du suivi (moyenne de 3,6 mois). Résultats : Nous avons obtenu un succès technique chez neuf patients à la fin de l'embolisation, avec exclusion angiographique complète de la fistule. Deux patients avaient une petite fistule résiduelle à la fin de l'embolisation, dont un présentait un léger drainage veineux cortical résiduel. Ces deux patients étaient stables à l'angiographie de suivi. Un patient avait une fistule résiduelle nourrie par l'artère ophtalmique dont l'embolisation a été jugée trop risquée. Il a été référé en chirurgie et l'intervention a été un succès. Chez un patient, le microcathéter s'est rompu et un fragment distal du microcathéter s'est logé dans l'artère occipitale. Il a été laissé en place. Aucune complication clinique n'a été observée au cours du suivi clinique (moyenne de 3,3 mois) dans cette série de cas. Nous avons constaté que deux patients avaient reçu une dose importante de radiation. Conclusion : Selon notre expérience, le traitement endovasculaire des fistules durales artério-veineuses intracrâniennes avec drainage cortical veineux direct par embolisation d'Onyx par voie artérielle constitue un traitement sûr et efficace. La durée de la fluoroscopie et la dose de radiation peuvent être une source de préoccupation.

Can. J. Neurol. Sci. 2009; 36: 168-175

Intracranial dural arteriovenous fistulas (DAVFs) are lesions with a heterogeneous clinical course, related to the varying patterns of venous drainage. Dural arteriovenous fistulas without cortical venous involvement tend to be relatively benign in course, while lesions with cortical venous drainage (whether direct or via reflux from dural venous sinuses) are more aggressive, having a higher rate of clinical presentation with aggressive neurological symptoms and intracranial haemorr-
From the Division of Neuroradiology, Department of Radiology (JC), Vancouver General Hospital, Vancouver, BC; Département de radiologie (AW, FG, JR, MEA, DR), Centre Hospitalier de l'Université de Montréal, Hôpital Notre-Dame, Montreal, QC, Canada.

Received September 4, 2008. Final Revisions Submitted November 12, 2008. Correspondence to: Jason Chew, Division of Neuroradiology, Department of Radiology, Vancouver General Hospital, 855 West 12th Avenue, Vancouver, British Columbia, V5Z 1M9, Canada. 
hage $\mathrm{e}^{1-3}$. The natural history of these high grade lesions has shown to yield a high annual mortality and morbidity rate if untreated ${ }^{4}$. Radiographic grading systems are therefore based around this correlation between venous drainage and pattern of clinical behaviour. ${ }^{1,5}$

Treatment of DAVFs has also been similarly stratified. Lesions without cortical venous drainage may be treated conservatively. When active treatment is indicated, it can be performed by exclusion of the fistula on the venous side by transvenous segmental coil occlusion of the dural venous sinus, with or without accompanying arterial embolisation ${ }^{6}$. This treatment has been proven to be safe and effective in selected cases, with low rates of thrombotic or haemorrhagic complications ${ }^{6}$ and is often the preferred approach for fistulas involving sinuses with cortical venous reflux. Lesions with direct cortical venous drainage, however, have been historically more difficult to treat, carrying a higher risk of haemorrhagic complication and failure of treatment. Retrograde catheterisation of veins is challenging with the risk of perforation. Occlusion adjacent to but not including the fistula site may also raise the venous pressure and precipitate rupture. Arterial embolisation may also be challenging, as there may be many separate feeders to the point of fistula. If arterial embolisation with n-butyl-2-cyanoacrylate (nBCA) is employed, this can require embolisation of many individual arteries and possibly occlusion of access points to the fistula without exclusion of the fistula. Embolisation of particles has proven to be of limited use in reducing flow rate, but may have only a temporary result and is generally not curative. Surgery and radiotherapy have also been employed for the treatment of these lesions with varying success, with or without adjuvant arterial embolisation with $\mathrm{nBCA}^{7-9,5}$, however radiotherapy is not immediately curative, requiring a period of some months for the fistula to close after treatment, during which time it is not protected from haemorrhage.

Recently, ethylene vinyl alcohol (Onyx) has been used to treat high-grade fistulas with some success ${ }^{10-14}$. We report our single centre experience with arterial Onyx embolisation for the treatment of DAVFs with direct cortical venous drainage.

\section{Materials ANd Methods}

We performed a retrospective analysis of all embolisation cases and review of charts and radiographic imaging for patients treated for DAVF after January 2004. Between January 2004 and April 2008, twelve consecutive high-grade intracranial dural arteriovenous fistulas were treated by trans-arterial embolisation with Onyx. Nine patients had Cognard type III and three patients had Cognard type IV lesions. There were six males and six females. Average age was 53.4 years (range 31 - 82 years). Patients presented with subarachnoid haemorrhage (1), subdural and subarachnoid haemorrhage (2), pulsatile tinnitus (1), convulsion (1), scleral injection and exophthalmos (1), dizziness

Table 1: Clinical presentation and angiographic appearance

\begin{tabular}{|c|c|c|c|c|c|c|}
\hline $\begin{array}{r}\mathrm{Pt} \\
\text { No. }\end{array}$ & Gender & $\begin{array}{c}\text { Age } \\
\text { at } \\
\text { embo }\end{array}$ & Clinical presentation & Location of fistula & $\begin{array}{c}\text { Grade } \\
(\text { Cognard })\end{array}$ & Feeders \\
\hline 1 & $\mathrm{~F}$ & 31 & Bruit & $\begin{array}{l}\text { Middle cranial fossa } \\
R\end{array}$ & III & Middle meningeal $\mathrm{R}$ \\
\hline 2 & $\mathrm{~F}$ & 57 & Hydrocephalus & Falco-tentorial & IV & $\begin{array}{l}\text { Middle meningeal L, Posterior cerebral L, marginal } \\
\text { tentorial bilateral }\end{array}$ \\
\hline 3 & M & 63 & $\begin{array}{l}\text { Epilepsy, Residual fistula } \\
\text { after previous attempt at } \\
\text { embolisation with coils at } \\
\text { another institution }\end{array}$ & $\begin{array}{l}\text { Superior sagittal } \\
\text { sinus }\end{array}$ & III & $\begin{array}{l}\text { Middle meningeal } \mathrm{R} \text {, superficial temporal bilateral } \\
\text { and occipital } \mathrm{R} \text {, anterior falcine (ophthalmic artery) }\end{array}$ \\
\hline 4 & M & 42 & $\begin{array}{l}\text { Pressure in the head with } \\
\text { exercise (Rt frontal) }\end{array}$ & Tentorial & III & $\begin{array}{l}\text { Occipital R, Middle meningeal R, Posterior } \\
\text { cerebral R }\end{array}$ \\
\hline 5 & $\mathrm{~F}$ & 34 & Convulsion & $\begin{array}{l}\text { Superior sagittal } \\
\text { sinus }\end{array}$ & III & Middle meningeal bilateral \\
\hline 6 & $\mathrm{~F}$ & 58 & Red eye L, exophthalmos & $\begin{array}{l}\text { Spheno-parietal } \\
\text { sinus and vein of } \\
\text { Trolard L }\end{array}$ & III & Ophthalmic L, Middle meningeal L \\
\hline 7 & M & 65 & Dizziness & $\begin{array}{l}\text { Superior sagittal } \\
\text { sinus }\end{array}$ & IV & Middle meningeal bilateral \\
\hline 8 & $\mathrm{M}$ & 47 & $\mathrm{SAH} \& \mathrm{SDH}$ & Tentorial & III & Middle meningeal $\mathrm{R}$ and occipital $\mathrm{R}$ \\
\hline 9 & M & 71 & $\mathrm{SAH}$ & $\begin{array}{l}\text { Falx cerebelli (below } \\
\text { tentorium) }\end{array}$ & IV & Occipital L, posterior meningeal L \\
\hline 10 & $\mathrm{~F}$ & 82 & $\begin{array}{l}\text { Incidental (found during } \\
\text { embolisation for Lt } \\
\text { cavernous sinus dural } \\
\text { fistula) }\end{array}$ & $\begin{array}{l}\text { Sphenoparietal sinus } \\
\text { Rt }\end{array}$ & III & Middle meningeal $\mathrm{R}$ \\
\hline 11 & M & 40 & $\begin{array}{l}\text { Incidental (cranial CT for } \\
\text { occipital osteoma) }\end{array}$ & Anterior falcine & III & Anterior cerebral bilateral, middle meningeal $R$ \\
\hline 12 & $\mathrm{~F}$ & 51 & SAH \& SDH & $\begin{array}{l}\text { Superior sagittal } \\
\text { sinus }\end{array}$ & III & Posterior meningeal L \\
\hline
\end{tabular}

$\mathrm{SAH}=$ subarachnoid haemorrhage; $\mathrm{SDH}=$ subdural haemorrhage; $\mathrm{CT}=$ computed tomography; Pt No. = Patient number; embo = embolisation; $\mathrm{R}=$ right; $\mathrm{L}=$ left 
(1), hydrocephalus (1), sensation of pressure in the head with exercise (1), residual fistula following previous embolisation attempt at a different institution (1) or as an incidental finding on cranial CT (2). The locations of fistulas included tentorial or falcine (4), superior sagittal sinus (4), sphenoparietal sinus (2), sigmoid and transverse sinus (1) and middle cranial fossa (1).

Each patient was treated under general anaesthesia in a biplane angiographic suite (Axiom Artis, Siemens). Femoral arterial access was obtained using the Seldinger technique and a short 6 French femoral arterial sheath placed, with continuous infusion of heparinised normal saline. Catheter angiography of the cranial vasculature was performed, including the common carotid, internal and external carotid and vertebral arteries, to demonstrate site of fistula and potential feeders. Images of the true venous phase of internal carotid injections were analysed to determine location of normal cerebral veins and direction of flow and patency of dural venous sinuses. These were compared with images of the arterialised venous structures draining the fistula. Using co-axial technique, a flow-directed microcatheter (Marathon or Ultraflow; ev3) was then advanced to the feeding artery using a road-map technique over a guide wire (X-Pedion or Mirage; ev3), as close as possible to the fistula site. Angiographic images were obtained through the microcatheter using a $3 \mathrm{cc}$ or $1 \mathrm{cc}$ syringe. These images were useful to determine the rate of flow through the fistula and proximity of the microcatheter tip, as well as the length of safety zone around the microcatheter for Onyx reflux. Ideally, the microcatheter tip would be wedged in the feeding artery providing superior control of forward flow of Onyx and reduced reflux, a technique which can also be used with nBCA injection ${ }^{15}$. The microcatheter was then flushed with heparinised normal saline. The microcatheter hub was bathed in dimethyl-sulfoxide (DMSO) and the dead space within the microcatheter filled by slow injection of DMSO $(0.25 \mathrm{cc})$. Onyx-18 was then injected very slowly to fill the dead space and continued very slow injection was observed using a blank road map technique. Bi-femoral puncture was also favoured in some cases to provide for control angiograms of other feeding vessels during embolisation.

Typically, Onyx would flow in an antegrade direction for some distance before occurrence of reflux around the catheter tip. At this point, the injection would be stopped for a period of time, usually one to three minutes before commencing again with caution and a refreshed subtraction mask. This cycle may be repeated many times until an end point of injection through that particular pedicle was reached. The goal was to advance Onyx through the fistula site supplied by the embolised feeder and

Table 2: Treatment and outcome

\begin{tabular}{|c|c|c|c|c|c|c|c|c|}
\hline $\begin{array}{r}\mathrm{Pt} \\
\text { No. }\end{array}$ & $\begin{array}{l}\text { Feeders } \\
\text { embolised }\end{array}$ & $\begin{array}{l}\text { Other } \\
\text { embolics } \\
\text { used }\end{array}$ & $\begin{array}{l}\text { Technical } \\
\text { success }\end{array}$ & Complications & $\begin{array}{l}\text { Time to last } \\
\text { angiographic } \\
\text { FU (months) }\end{array}$ & $\begin{array}{l}\text { Angiographic } \\
\text { Fistula } \\
\text { Exclusion }\end{array}$ & \begin{tabular}{|} 
Time to last \\
clinical FU \\
(months)
\end{tabular} & Outcome \\
\hline 1 & MMA R & $\mathrm{N}$ & $\bar{Y}$ & $\mathrm{~N}$ & 4.3 & $\bar{Y}$ & 2.3 & Fistula excluded \\
\hline 2 & MMA L & $\mathrm{N}$ & $\mathrm{Y}$ & $\mathrm{N}$ & 2.6 & $\mathrm{Y}$ & - & Fistula excluded \\
\hline 3 & MMA R & $\mathrm{N}^{*}$ & Partial & $\mathrm{N}$ & 1.5 & Y & 3.2 & $\begin{array}{l}\text { Obliteration of high grade fistula. } \\
\text { Residual second 'benign' fistula }\end{array}$ \\
\hline 4 & $\begin{array}{l}\text { OA R, MMA } \\
\mathrm{R}\end{array}$ & $\mathrm{N}$ & Y & $\begin{array}{c}\mathrm{Y}- \\
\text { microcatheter } \\
\text { rupture }\end{array}$ & 0.2 & Y & - & Fistula excluded \\
\hline 5 & MMA L & $\mathrm{N}$ & $\mathrm{Y}$ & $\mathrm{N}$ & - & - & 1.2 & Fistula excluded \\
\hline 6 & MMA L & $\mathrm{N}$ & $\begin{array}{l}N \text { (residual } \\
\text { fistula via } \\
\text { ophthalmic } \\
\text { artery) }\end{array}$ & $\mathrm{N}$ & 0.8 & $\mathrm{Y}$ & - & Surgery \\
\hline 7 & MMA R & $\mathrm{N}$ & $\mathrm{Y}$ & $\mathrm{N}$ & 12 & $\mathrm{Y}(\mathrm{MRI})$ & 10.9 & Fistula excluded \\
\hline 8 & MMA R & N & Y & N & 4 & Y & 4.8 & Fistula excluded \\
\hline 9 & $\begin{array}{l}\text { Onyx in } L \\
\text { PMA only }\end{array}$ & $\begin{array}{c}Y-\text { particles } \\
\text { L OA }\end{array}$ & Y & $\mathrm{N}$ & 6 & $\mathrm{Y}(\mathrm{MRI})$ & 1.5 & Fistula excluded \\
\hline 10 & MMA R & $\mathrm{Y}^{+}$ & Partial & $\mathrm{N}$ & 2.7 & $\mathrm{~N}$ & 1.2 & $\begin{array}{l}\text { Residual R sphenoid wing fistula } \\
\text { asymptomatic. Cavernous sinus } \\
\text { fistula obliterated (see Table 1). }\end{array}$ \\
\hline 11 & $\begin{array}{l}\text { ACA } L \text { and } \\
\text { MMA R }\end{array}$ & Histo-acry| ${ }^{\#}$ & Y & $\mathrm{N}$ & 2 & Y & 1 & Fistula excluded \\
\hline 12 & L PMA & $\mathrm{N}$ & Y & N & 2.5 & 2.5 & 2 & Fistula excluded \\
\hline
\end{tabular}

$\mathrm{MMA}=$ Middle meningeal artery $\mathrm{OA}=$ Occipital artery; $\mathrm{PMA}=$ posterior meningeal artery; $\mathrm{ACA}=$ anterior cerebral artery; $\mathrm{AVM}=$ arteriovenous malformation; EEG = electroencephalography; MRI = magnetic resonance imaging; $\mathrm{R}=$ right; $\mathrm{L}=$ left; $\mathrm{N}=\mathrm{No}$; $\mathrm{Y}=$ Yes; Pt. No = Patient number; FU = follow-up; * patient had a previous attempted embolisation by mircrocoils at another institution with subsequent recanalisation of feeder arteries; +Coils were placed first in a branch to redirect embolic material to the fistula.

\# Histo-acryl was used after Onyx for residual small feeders with small persistent fistula with persisting cortical venous drainage 


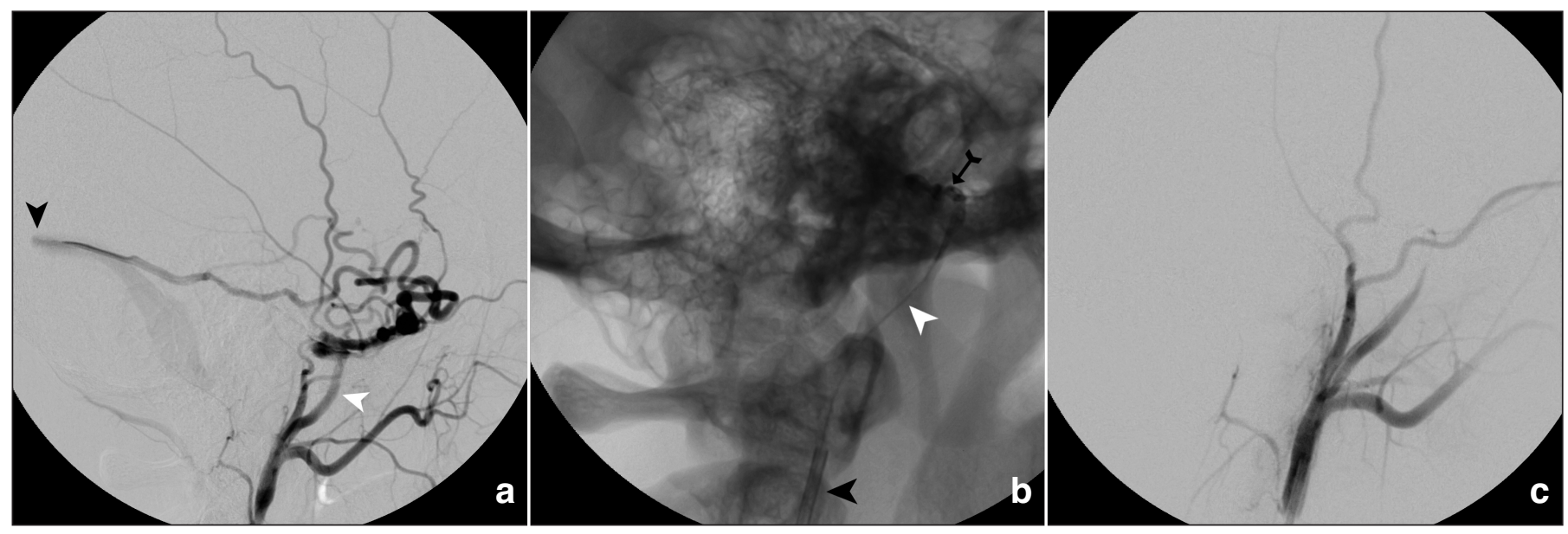

Figure 1: Patient 1.a) External carotid artery (ECA) angiogram (lateral). Middle meningeal artery (MMA) (white arrowhead) supplies fistula draining to the sigmoid sinus (black arrowhead). b) Lateral spot film. Guide catheter (black arrowhead), microcatheter in MMA (white arrowhead) and site of fistula (black arrow).c) Completion ECA angiogram showing complete obliteration of fistula.

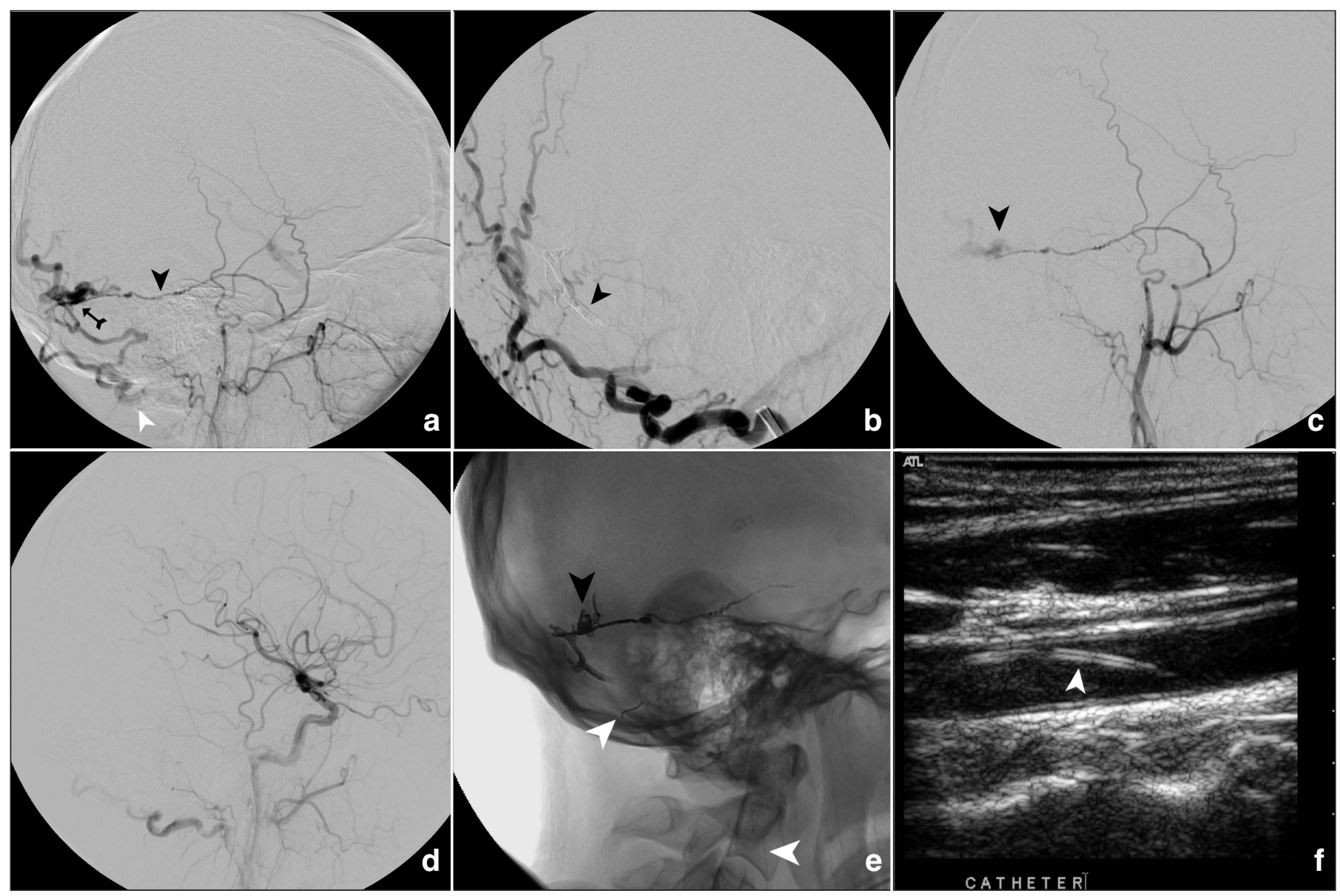

Figure 2: Patient 4. a) External carotid artery (ECA) angiogram (lateral). Middle meningeal artery (MMA) supply (black arrowhead), site of fistula (black arrow) and draining occipital veins (white arrowhead). b) Occipital artery angiogram. Subtraction artifact around Onyx cast (arrowhead). No residual fistula from occipital artery. c) ECA angiogram. Small residual fistula (black arrowhead) from MMA. d) Completion ECA angiogram after second embolisation in MMA during same session. No residual fistula. e) Spot film (lateral). Onyx cast at fistula site (black arrowhead). Glued microcatheter (white arrowheads).f) Six month ultrasound. Microcatheter in common carotid artery. 
reflux Onyx into the other feeding arteries, thereby obliterating the lesion. Injections were stopped when this goal was achieved as confirmed by control injection through the guiding catheter, but other end points were also used. These included dangerous reflux of Onyx, either to a point proximally on the microcatheter where retrieval may become difficult, or reflux nearing an artery supplying a cranial nerve, typically the facial nerve when embolising the middle meningeal artery. Onyx passage into the vein was treated with caution, but would not necessarily result in immediate cessation of the injection, as at that point, the presence of Onyx may raise the venous pressure distal to the fistula if the fistula was still patent, and as such we redoubled our efforts for a complete exclusion. After reaching an end point, the microcatheter was retrieved with continuous gentle traction and aspiration through a syringe on the microcatheter hub, as there is a potential for some Onyx at the tip of the microcatheter to remain liquid and enter the guiding catheter during microcatheter retrieval. The patients were observed overnight in our stroke and endovascular unit and a routine cranial CT scan was performed the following day. Elective patients were discharged home from hospital the day after embolisation. Clinical follow-up with or without catheter angiography was performed at six weeks postembolisation by an interventional neuroradiologist, depending on the clinical outcome.

The majority of cases were treated by Onyx embolisation alone (Table 1). One case had embolisation with n-butyl-2cyanoacrylate at the start of the session with minimal result, followed by Onyx (Patient 11). One patient had particle embolisation prior to Onyx to reduce flow velocities (Patient 9). One patient had already had a prior attempt at embolisation at another institution using coils, without success (Patient 3). Imaging follow-up was obtained in all but one patient (mean 3.6 months). Two patients had follow-up MRI instead of angiography, although catheter angiography was preferred for diagnosis and follow-up.

\section{Results}

Nine patients had a technical success at the end of the embolisation procedure with complete angiographic exclusion of the fistula (Table 2). Two patients had a small residual fistula at the end of embolisation, one of which had residual mild cortical venous drainage and one of which was a distinct adjacent fistula (Cognard I). Both were stable at follow-up angiography. Finally, one patient had a residual fistula supplied by the ophthalmic artery, which was thought to be unsafe to embolise and was sent for surgery which was successful.

No clinical complications were observed in this series initially or at clinical follow-up (mean 3.3 months). In one patient the microcatheter ruptured during injection, with a fragment of the distal microcatheter remaining in the occipital artery extending down to the common carotid to the C6 vertebral level. This patient received a two month course of aspirin and had no clinical consequence.

Long subtracted fluoroscopy times were noted for many of the patients in this series, with two patients having close to or more than two hours of fluoroscopy time (Patients 10 and 11). These patients had complex fistulas which were difficult to treat, requiring lengthy injections. Radiation doses for each were 12000 and 7177 mGy respectively.

\section{Illustrative cases}

Patient 1 - Female patient 31-years-old, presenting with a five year history of unilateral right sided bruit. Angiography showed an intracranial dural arteriovenous fistula, Cognard grade III, fed by the right middle meningeal artery and drained by a cortical vein superficially to the right transverse - sigmoid sinus junction and another vein centrally to the great vein of Galen via the basal vein of Rosenthal. Embolisation was performed via the right middle meningeal artery with injection of Onyx resulting in an angiographic and clinical cure. The patient remained asymptomatic at clinical follow-up in ten weeks and at follow-up angiography in four and a half months the fistula remained excluded.

Patient 4 - Male patient 42-years-old, presenting with symptoms of pressure in the head during exercise. An MRI at another institution revealed abnormal vessels in the right occipital region. Angiography confirmed a Cognard type III dural arteriovenous fistula supplied by branches of the right middle meningeal and occipital arteries (with some anastomoses from occipital branches of the right vertebral) and draining via occipital cortical veins eventually to the superior sagittal sinus. Embolisation with Onyx was performed via the right occipital artery initially, with reduction in flow across the fistula, although complicated by perforation of the microcatheter during injection, resulting in a fragment of microcatheter left in the occipital artery down to the common carotid. A subsequent injection of Onyx via the right middle meningeal artery obliterated the fistula. No subsequent clinical complications were noted related to either the embolisation or the retained microcatheter fragment.

Patient 11 - Male patient 39-years-old, who presented initially with a palpable lump in the left occipital region. He was otherwise asymptomatic. The CT scan and subsequent MRI showed the palpable lesion to be an outer table cranial osteoma, but also revealed the presence of abnormal dilated vessels in the anterior inter-hemispheric fissure. Catheter angiography was interpreted as an arteriovenous malformation supplied by the right anterior cerebral artery. The patient proceeded to embolisation via the right anterior cerebral artery, performed through microcatheter injection of nBCA mixed with lipiodol. The first injection however did not result in closure of the fistula and the true nature of the lesion was at that time suspected. Left external carotid injections revealed a Cognard grade III dural arterio-venous fistula, supplied by the left middle meningeal artery. Embolisation via the middle meningeal artery was then performed using the Onyx technique as described above, with complete exclusion of the fistula by injection of one pedicle. Incidental note was also made of a Cognard grade I fistula from the left ophthalmic artery to the superior sagittal sinus, which was left untreated. Follow-up angiography two months later confirmed an angiographic cure of the high grade fistula, with the second, benign fistula unchanged. The patient remained asymptomatic at clinical follow-up in one month.

Patient 12 - Female patient 51-years-old, who collapsed unconscious with a Glasgow Coma Scale score of 4 to 5, pupillary dilatation and decerebrate posturing on the left and with right hemirigidity. An unenhanced cranial CT scan revealed a large left sided pan-hemispheric subdural haematoma with severe midline shift to the right and with subarachnoid blood and a small left occipital intraparenchymal haematoma. Urgent 

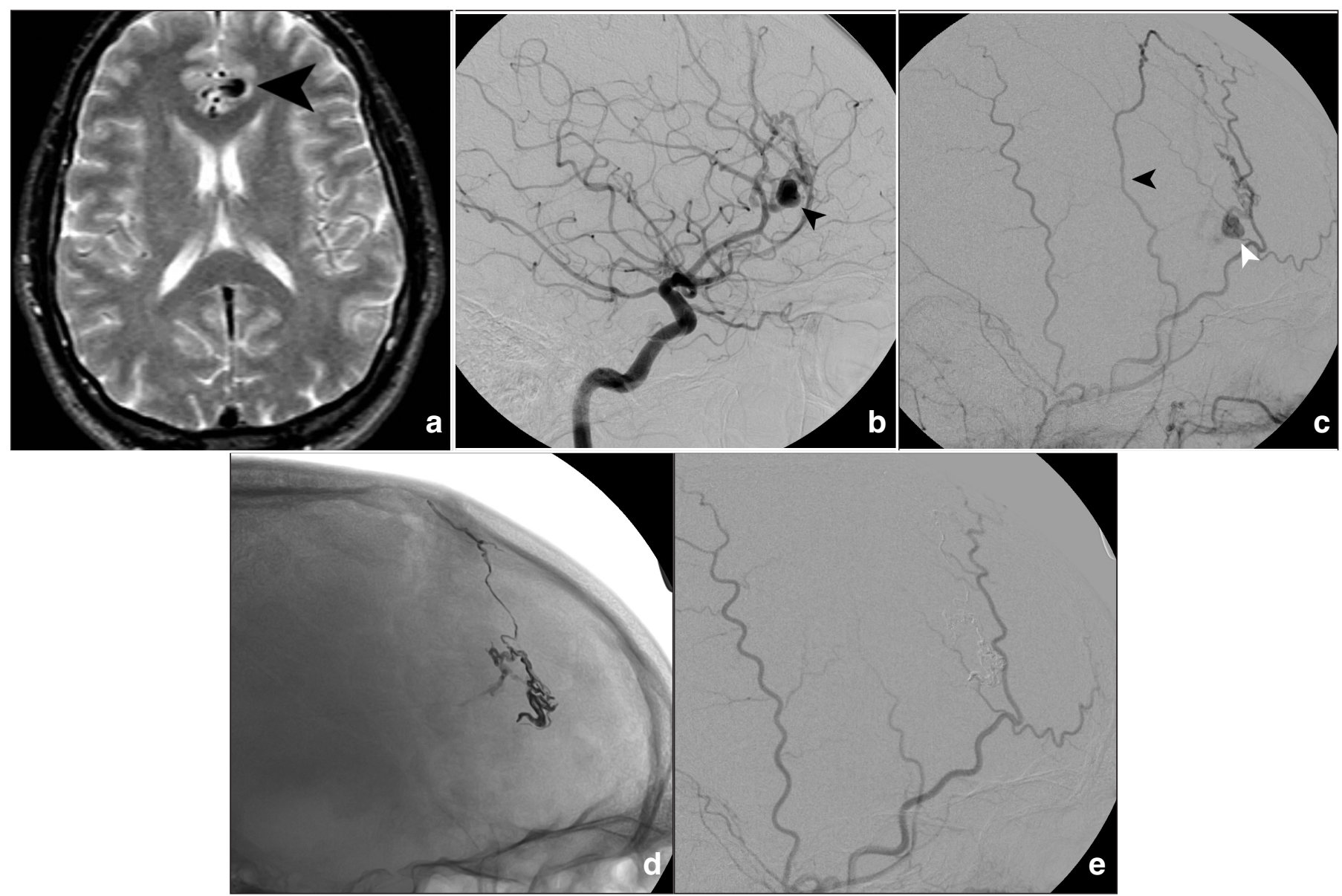

Figure 3: Patient 11. a) Axial T2 MRI. Abnormal vessels in anterior interhemispheric fissure (arrowhead). b) Internal carotid artery (ICA) angiogram (lateral). Venous pouch (arrowhead) with surrounding dilated veins supplied by anterior cerebral artery. c) External carotid artery (ECA) angiogram (lateral). Middle meningeal artery (MMA) (black arrowhead) supplying fistula with venous pouch again seen (white arrowhead). d) Spot film (lateral). Onyx cast. e) Completion ECA angiogram (lateral). Complete obliteration of fistula.

craniotomy was performed to decompress the subdural haematoma. A subsequent angiogram showed the presence of a high grade DAVF in the left occipital region, fed by the left posterior meningeal artery, with some collateral supply from the left external carotid. The patient proceeded to embolisation via the left posterior meningeal artery with Onyx. On the initial injection, Onyx passed directly into the draining vein. This was thought to be due to the very distal location of the microcatheter tip, which was at the level of the fistula. The microcatheter was withdrawn slightly and further injection of Onyx filled the site of fistula and refluxed back into the feeding arteries, resulting in a complete closure of the fistula. At clinical follow-up two months later the patient had made a spectacular clinical recovery, although with continued easy fatigability. Angiography performed another two weeks later showed complete exclusion of the fistula.

\section{Discussion}

Endovascular treatment of low grade DAVFs by the transvenous route has been used successfully for over ten years now. ${ }^{6}$ High grade DAVFs however have remained somewhat of a challenge to treat. Onyx provides us with a novel technique for arterial embolisation due to its substantially different handling characteristics when compared to nBCA. Onyx is a non-adhesive precipitate, whereas $\mathrm{nBCA}$ is a polymer. Onyx is more cohesive and tends to layer concentrically within the artery whereas nBCA tends to form discrete plugs which may fragment and propagate antegrade with flow, which can potentially result in uncontrolled venous passage of nBCA with the risk of major haemorrhagic complication. Onyx does not tend to fragment, resulting in a continuous cast. These properties allow for much slower and controlled injections. As the Onyx advances into vessels thought desirable to be embolised, the rate of injection can be slightly increased to allow continued 'momentum', whereas when Onyx refluxes around the microcatheter tip, the injection can be 


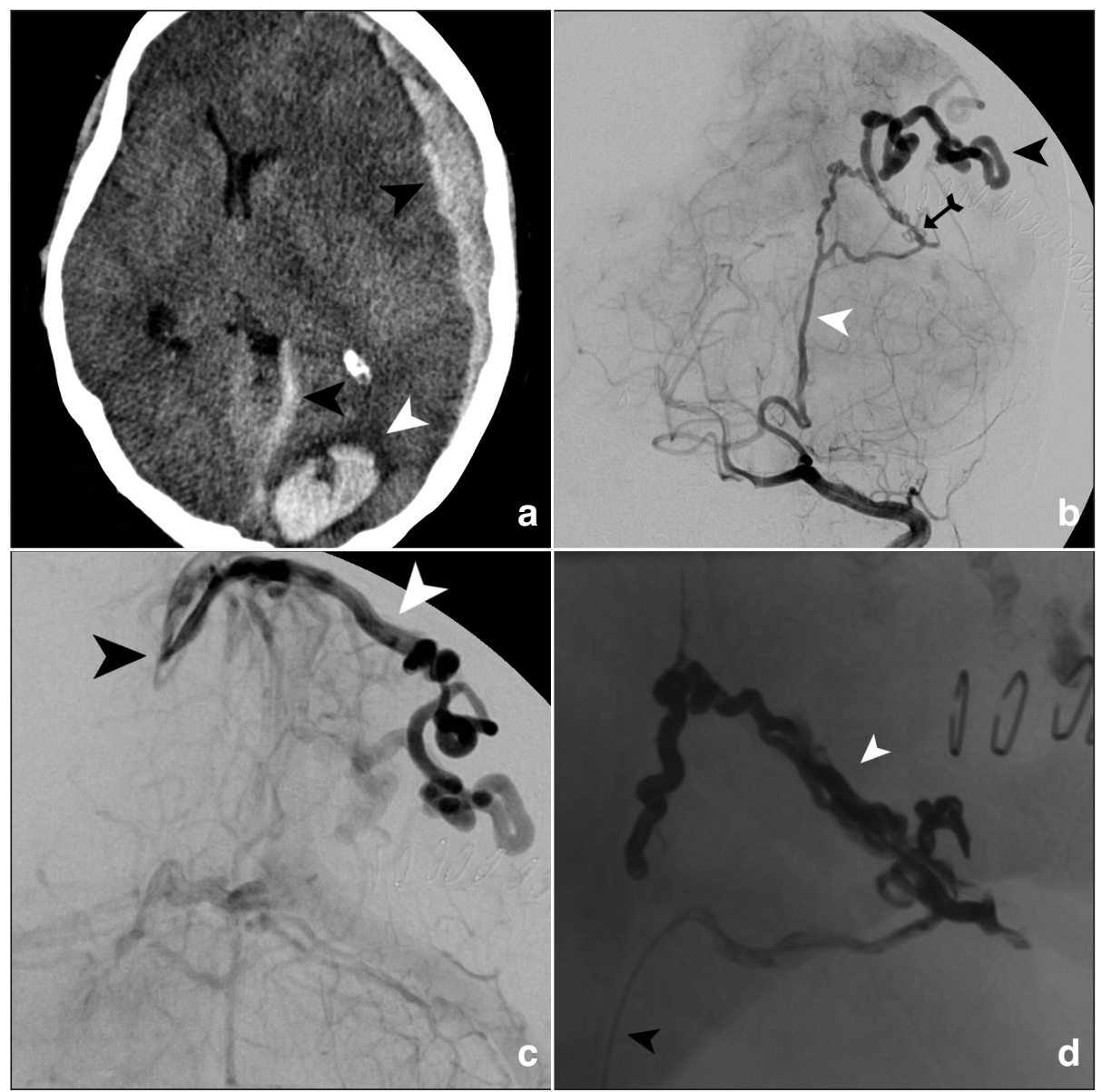

Figure 4: Patient 12. a) Non-enhanced CT at presentation. Subdural (black arrowheads) and intraparenchymal (white arrowhead) haematomas. Significant mass effect is evident. b) Left vertebral angiogram antero-posterior (AP) post-op external ventricular drain (EVD) and evacuation of haematoma. Posterior meningeal artery (white arrowhead) supplying fistula (black arrow) with draining vein (black arrowhead). c) Left vertebral angiogram (AP). Draining vein (white arrowhead) feeds into superior sagittal sinus (black arrowhead).d) Spot film. Microcatheter (black arrowhead) and Onyx cast (white arrowhead).

stopped for a few minutes to allow formation of a plug of Onyx around the microcatheter tip, in order to encourage antegrade flow with subsequent injections.

The concentric flow of Onyx along the walls of the artery also allows the substance to flow through the fistula site and then reflux into other adjacent feeding arteries, which in turn allows for a complete cure with injection from one pedicle, whereas with nBCA more pedicles must be embolised individually, which may result in a long and often incomplete embolisation. Of course care must often be taken to avoid reflux into arteries which supply normal neurological structures, in particular the cranial nerves, especially the VII nerve when injecting from the middle meningeal artery. This may prevent the use of Onyx in fistulas located at the base of skull, near important cranial nerves.

The use of Onyx for intracranial intra-arterial injection has been established for treatment of brain arteriovenous malformations $^{16-18}$ and was approved by the Food and Drug Administration (FDA) in July 2005 for such cases.
In our experience with Onyx for trans-arterial embolisation of high grade DAVFs, the technique produced no clinical complications and had a high rate of complete obliteration following only one embolisation session. Often this was achieved with injection of just one feeding artery. A bilateral femoral approach is useful when the fistula is fed by many arteries to look for reflux into other feeders during the embolisation. Limited angiographic and clinical follow-up of treated lesions did not demonstrate any recurrent fistulas. Although our numbers were small and the follow-up short, this suggests a possibility of long term cure by this technique.

One of the drawbacks of using Onyx for these types of DAVFs is that a long fluoroscopy time and thus a higher radiation dose also accompany the long injection time. This has had some temporary side effects in a few of our patients, most notably transient hair loss. Of course care must be taken to attempt to limit radiation dose, but with this kind of treatment it is necessary to inject under continuous fluoroscopy in order to 
avoid reflux into collateral vessels giving supply to normal neurologic structures. Treatment of the most complex fistulas in this series with extensive feeding networks came at a cost of significant radiation dose.

Onyx can be used safely and effectively to treat high grade DAVFs by trans-arterial embolisation, with a very high rate of complete cure in one session, often via a single pedicle. This treatment should be considered as a viable option for the initial (and frequently sole) therapy for patients with high grade DAVFs, although this may come with a cost of significant radiation dose.

\section{REFERENCES}

1. Cognard C, Gobin YP, Pierot L, Bailly AL, Houdart E, Casasco A, et al. Cerebral dural arteriovenous fistulas: clinical and angiographic correlation with a revised classification of venous drainage. Radiology. 1995;194(67):671-80.

2. Satomi J, van Dijk MC, terBrugge KG, Willinsky RA, Wallace MC. Benign cranial dural arteriovenous fistulas: outcome of conservative management based on the natural history of the lesion. J Neurosurg. 2002;97:767-70.

3. van Rooij WJ, Sluzewski M, Beute GN. Dural arteriovenous fistulas with cortical venous drainage: incidence, clinical presentation, and treatment. AJNR Am J Neuroradiol. 2007 Apr; 28(4):651-5.

4. van Dijk MC, terBrugge KG, Willinsky RA, Wallace MC. Clinical course of cranial dural arteriovenous fistulas with long-term persistent cortical venous reflux. Stroke. 2002;33:1233-6.

5. Borden JA, Wu JK, Shucart WA. A proposed classification for spinal and cranial dural arteriovenous fistulous malformations and implications for treatment. J Neurosurg. 1995 Feb;82(2): 166-79.

6. Roy D, Raymond J. The role of transvenous embolization in the treatment of intracranial dural arteriovenous fistulas. Neurosurgery. 1997;40:1133-41.

7. Pan DH, Chung WY, Guo WY, Wu HM, Liu KD, Shiau CY, et al. Stereotactic radiosurgery for the treatment of dural arteriovenous fistulas involving the transverse sinus. J Neurosurg. 2002;96: 823-9.
8. Lewis AI, Tomsick TA, Tew JM Jr. Management of tentorial dural arteriovenous malformations: transarterial embolization combined with stereotactic radiation or surgery. J Neurosurg. 1994 Dec;81(6):851-9.

9. Friedman JA, Pollock BE, Nichols DA, Gorman DA, Foote RL, Stafford SL. Results of combined stereotactic radiosurgery and transarterial embolization for dural arteriovenous fistulas of the transverse and sigmoid sinuses. J Neurosurg. 2001 Jun;94(6): 886-91.

10. Toulgoat F, Mounayer C, Túlio Salles Rezende M, Piotin M, Spelle L, Lazzarotti G, et al. Embolisation par voie artérielle de malformations artérioveineuses durales intracrâniennes à l'aide d'ethylvinyl alcool copolymère (Onyx $\left.{ }^{\circledR} 18\right)$. J Neuroradiol. 2006;33:105-14.

11. Carlson AP, Taylor CL, Yonas H. Treatment of dural arteriovenous fistula using ethylene vinyl alcohol (Onyx) arterial embolization as the primary modality: short-term results. J Neurosurg. 2007; 107:1120-5.

12. Arat A, Inci S. Treatment of a superior sagittal sinus dural arteriovenous fistula with Onyx: technical case report. Neurosurgery. 2006 Jul;59(1 Suppl 1):ONSE169-70; discussion ONSE169-70.

13. Cognard C, Januel AC, Silva NA Jr, Tall P. Endovascular treatment of intracranial dural arteriovenous fistulas with cortical venous drainage: new management using Onyx. AJNR Am J Neuroradiol. 2008 Feb;29(2):235-41.

14. Nogueira RG, Dabus G, Rabinov JD, Eskey CJ, Ogilvy CS, Hirsch JA, et al. Preliminary experience with onyx embolization for the treatment of intracranial dural arteriovenous fistulas. AJNR Am J Neuroradiol. 2008 Jan;29(1):91-7.

15. Nelson PK, Russell SM, Woo HH, Alastra AJ, Vidovich DV. Use of a wedged microcatheter for curative transarterial embolization of complex intracranial dural arteriovenous fistulas: indications, endovascular technique, and outcome in 21 patients. $\mathrm{J}$ Neurosurg. 2003 Mar;98(3):498-506.

16. Mounayer C, Hammami N, Piotin M, Spelle L, Benndorf G, Kessler I, et al. Nidal embolization of brain arteriovenous malformations using Onyx in 94 patients. AJNR Am J Neuroradiol. 2007 Mar;28(3):518-23.

17. Weber W, Kis B, Siekmann R, Kuehne D. Endovascular treatment of intracranial arteriovenous malformations with onyx: technical aspects. AJNR Am J Neuroradiol. 2007 Feb;28(2):371-7.

18. van Rooij WJ, Sluzewski M, Beute GN. Brain AVM embolization with Onyx. AJNR Am J Neuroradiol. 2007 Jan;28(1):172-7. 